\title{
UMA NOVA MULHER [?]: GÊNERO FEMININO NA FILMOGRAFIA CONTEMPORÂNEA DA DISNEY
}

\author{
A NEW WOMAN (?]: FEMINNNE GENDER IN DISNEY CONTEMPORARY FILMOGRAPHY
}

\begin{abstract}
RESUMO
O objetivo dessa pesquisa foi compreender os discursos (efeitos de sentidos) ligados ao gênero feminino e à heteronormatividade concernentes à filmografia contemporânea da Disney. Foram utilizados para a análise três filmes (Valente, 2012; Frozen, 2013; e Malévola, 2014) que compuseram o corpora de análise. Três Formações Discursivas (Feminilidade Hegemônica, Ato Heroico, Amor Romântico) foram constituídas e analisadas a partir da Análise do Discurso de tradição francesa de Michel Pêcheux. Essas animações estão dotadas de elementos simbólicos (explícitos e implícitos) que propiciam a discussão sobre o modo como o gênero feminino é representado, visto que sugerem fissuras tanto nas matrizes hegemônicas do feminino como na naturalizaçãoda heteronormatividade enquanto forma única de configuração das relações entre e intra os gêneros. Nominalmente, consideramos que essas produções cinematográficas são espaços discursivos de conflitos e tensões entre aspectos tradicionais e questionadores do gênero feminino na contemporaneidade.
\end{abstract}

Palavras-chave: Gênero. Cinema. Análise do discurso.

\begin{abstract}
The objective of this research was to understand discourses related to the feminine gender and heteronormativity concerning Disney contemporary filmography. Three films were used for the analysis (Brave, 2012; Frozen; 2013; Maleficent, 2014). Three discourses formations were built (Hegemonic Femininity; Heroic Act; Romantic Love) and analyzed through French Discourse Analysis according Michel Pêcheux. It was observed that these animations are endowed with symbolic elements that allow the discussion about how the feminine gender is represented, as suggests cracks in the hegemonic feminine gender and in the naturalization of heteronormativity between and within genders. These cinematographic productions were considered a discursive space of tension between traditional and innovative aspects of the feminine gender on contemporary times.
\end{abstract}

Keywords: Gender. Cinema. Discourse analysis.

Juliana M. Ruiz

Universidade Federal do Triângulo Mineiro (UFTM). E-mail: julianamruiz@hotmail.com

Rafael de Tilio

Universidade Federal do Triângulo Mineiro (UFTM). E-mail: rafaeldetilio.uftm@gmail.com 


\section{Introdução}

Temas relacionados às diferenças sexuais e de gênero estão presentes nos mais diversos discursos na história, sejam eles de cunho religioso, filosófico, biológico, psicológico, antropológico ou social. No entanto, é a partir do final do século XVIII que essas questões ganham destaque como objeto de análise científica (Araújo, 2005). Posteriormente, com o adensamento dos estudos e teorias de gênero nas décadas de 1980 e 1990, categorias e fronteiras sexuais consideradas imutáveis e universais ganham novos questionamentos e sentidos. Segundo Bourdieu (2007), a divisão do mundo pautada e justificada pelas diferenças biológicas (no que diz respeito à divisão sexual do trabalho, à reprodução biológica e social) opera como a mais fundada das ilusões coletivas.

O conceito de gênero diverge entre diferentes autores que se propõem a discutir essa temática. Gênero em sua forma gramatical serve para designar indivíduos de sexos diferentes ou corpos sexuados, sendo masculino ou feminino (Araújo, 2005). Porém, seu uso em sua forma mais recente deve-se aos movimentos feministas da década de 1960 e posteriores que a utilizam como forma de rejeição ao determinismo biológico, enfatizando o caráter social das distinções baseadas no sexo biológico (Scott, 1995). Ou seja, o gênero adquire a função de destacar as construções sociais acerca do esperado como ideal aos homens e mulheres num determinado momento histórico e/ ou agrupamento social. Nesse sentido, ganha relevância a noção de cultura, situando o gênero na esfera social e não no plano biológico.

Dois dos grandes nomes que se dedicam à definição e problematização do conceito gênero são Joan Scott e Judith Butler, sendo que ambas trazem perspectivas diferentes para a literatura científica. De acordo com Scott (1995: 21) a definição do conceito de gênero baseia-se na conexão entre duas proposições: "[gênero] é um elemento constitutivo das relações sociais baseado nas diferenças percebidas entre os sexos, e o gênero é uma forma primeira de significar as relações de poder". Scott mantém em sua conceituação traços do essencialismo biológico (a diferença sexual é biologicamente natural e a-histórica), mas desconsidera essa diferença como sendo fator que determina as características psicológicas, comportamentais e sociais de cada grupo - assim, é o gênero e não o sexo que transforma seres anatomicamente machos e fêmeas em homens e mulheres (Scott, 1995).

Por sua vez, Butler (2015) problematiza o sexo biológico como biologicamente natural e gênero como socialmente construído partindo da premissa de que o sexo também seria uma construção cultural/social assim como o gênero. Essa autora também traz algumas reflexões a respeito de questões teóricas a partir das quais os movimentos feministas se apoiam para tentar representar a mulher, visto que segundo seus argumentos, uma identidade (ou categoria) unívoca e fixa feminina que segmentos do movimento feminista tentam representar não existiria; a referência a esse grupo (mulher), portanto, deve ser sempre no plural (mulheres e feminilidades). 
Outra vertente que se propõe a problematizar o conceito gênero são as teorias queer. Queer é um termo com conotação negativa utilizado para aqueles que, dealguma forma, rompem com as normas estabelecidas de gênero e sexualidade (Jagose, 1996). De acordo com Seidman (1996: 13) queer pode ser compreendido como a investigação “(...) daqueles conhecimentos e práticas sociais que organizam a 'sociedade' como um todo, sexualizando - heterossexualizando ou homossexualizando - corpos, desejos, atos, identidades, relações sociais, conhecimentos, cultura e instituições sociais".

As teorias queer ressaltam o binarismo hetero/homossexual como forma de organização da vida social contemporânea, ou seja, não diferenciando a ordem social da sexual. Para entender a estrutura dessa ordem, é necessário tomar como ponto de partida esse binarismo e a priorização da heterossexualidade por meio de um dispositivo que a naturaliza e, ao mesmo tempo, torna-a compulsória. (Miskolci, 2009). Para os partidários dessa concepção o fundamento da ordem social vigente é a heteronormatividade (Warner, 1993). Esse conceito retrata as expectativas, demandas e obrigações sociais que decorrem do pressuposto da heterossexualidade como natural e, por conseguinte, fundamento de uma sociedade (Chambers, 2003).

Dessa forma, a partir desse campo de normalização decorrente da heteronormatividade é por intermédio das violências (reais e simbólicas, de diversas manifestações) que as estruturas sociais hegemônicas geram sujeitos designados como normais e naturais. Em contrapartida, os desviantes da conduta heteronormativa são considerados perversos ou patológicos (Warner, 1993). Por isso, a sexualidade é um dispositivo (histórico) do poder.

Dito isso, deve-se considerar que são diversos e recorrentes os estudos que destacam que produções artísticas e midiáticas são aparatos para discutir questões sociais, dentre elas o gênero. A mídia e suas repercussões adquiriram papel fundamental na sociedade contemporânea atuando como um sistema de significação, intercedendo nas relações entre sociedade e sujeito através de seus discursos (Fernandes \& Siqueira, 2010). Essas produções tornam-se agentes de identificações sobre o que é ou não desejável, esperado e aceitável em relação às atitudes dos indivíduos (Kellner, 2001).

De acordo com Freire (2005), a indústria cultural providencia inúmeras descrições tanto textuais como visuais do que seria conveniente ser assumido no que tange, inclusive, à sexualidade. Nesse sentido, De Lauretis (1994) afirma que gênero seria tanto um produto dessas diferentes tecnologias sociais (este é o termo utilizado pela autora para denominar o conjunto midiático que envolve rádio, televisão, cinema, jornais e, mais recentemente, a internet) como um resultado de práticas institucionalizadas e cotidianas. Emoutras palavras, as produções artísticas e midiáticas podem ser compreendidas como materializações do aparelho ideológicos do Estado de informação (Althusser, 2010), alvo e lugar da luta de classes e da constituição das subjetividades. Portanto, gênero não seria propriedade inerente aos corpos, mas sim efeito produzido nestes e nas relações sociais dos indivíduos.

A partir desse contexto, as produções cinematográficas configuram-se como um possível dispositivo tecnológico produtor e legitimador de identidades sociais e de gênero (Pires, 2009). Nos filmes de animação esse espaço de constituição de gênero 
pode ser observado nas narrativas que frequentemente atribuem as diferenças (físicas, comportamentais, psicológicas) ao sexo biológico das personagens (Sabat, 2001). Em consequência, constitui-se um ciclo (re) produtor de práticas sociais que sustentam padrões considerados ideais de identificações de gênero.

Diante do apresentado o objetivo dessa pesquisa é compreender os discursos (e seus efeitos de sentido) ligados ao gênero feminino e à heteronormatividade concernentes à filmografia contemporânea da Disney.

\section{Apontamentos sobre os procedimentos metodológicos}

Esta é uma pesquisa do tipo qualitativa, pautada na Análise do Discurso (doravante, AD) de linha francesa. Foram utilizados para a análise três filmes de animação produzidos pela empresa Walt Disney Pictures, a saber: Valente (2012), Frozen (2013) e Malévola (2014).

Em relação aos procedimentos de coleta e de análise dos dados é significativo, antes, considerar que a AD parte do pressuposto de que discurso é o lugar da relação entre linguagem e Ideologia (Orlandi, 2013), ou mais precisamente "(...) aquilo que numa formação ideológica dada [...] a partir de uma posição dada [...] pode e deve ser dito" (Pêcheux, 2014: 16o - grifo do original).

A AD permite que sejam utilizados como objetos de análise quaisquer materiais que produzam sentidos, tais como escrita, imagens, falas e outros (Caregnatto \& Mutt, 2006). Especificamente para a presente pesquisa os corpora de informação foi composto a partir de cenas e diálogos retirados de cada um dos três textos-filmes (corpus) da pesquisa (Valente; Frozen; e Malévola). Por corpus compreendemos:

(...) uma série de superfícies lingüísticas (discursos concretos) ou de objetos discursivos [...] estando estas superfícies dominadas por condições de produção estáveis e homogêneas [formações discursivas, formações ideológicas e Ideologia] (Pêcheux \& Fuchs, 1997: 182).

Portanto, os diálogos e cenas dos filmes podem ser considerados superfícies linguísticas afetadas pelo Esquecimento Número 1 (esquecimento da exterioridade do sujeito da própria Formação Discursiva [FD] e da Ideologia que o domina, ou seja, a impossibilidade de sozinho compreender as condições materiais e ideológicas que determinam suas possibilidades de dizer) e Esquecimento Número 2 (referente ao fato de que todo sujeito falante seleciona na FD que o domina enunciados, formas e sequências, ou seja, tem a ilusão de dominância de escolha do dizer) que necessitam de análise, ou seja, de serem transformadas em objetos discursivos e, depois, compreendidas como processo discursivo, ou seja, como produtores de efeitos de sentidos (Pêcheux \& Fuchs, 1997). 
A escolha destes três filmes fundamentou-se na hipótese de que essas produções (doravante denominados textos-filmes) contemporâneas supostamente questionam paradigmas de gênero (principalmente o feminino) adotados no cinema clássico das animações. Tal suposição parte dos analistas do discurso dessa pesquisa diante da constituição dos corpora que considera que os filmes de animação produzem sentidos por meio de seus discursos. Para a AD o posicionamento do analista e seus gestos de interpretação são elementos inerentes à construção de seu dispositivo analítico (Orlandi, 2013).

Para a AD de tradição francesa, nominalmente pela proposta por Michel Pêcheux, os discursos não são meras transmissões de informações, mas sim processos de posicionamento dos sujeitos, subjetivação e produções de sentidos (Orlandi, 2013). Nesse sentido, a AD visa compreender as articulações de como a linguagem está materializada na Ideologia e em como a Ideologia se manifesta na língua. Para tal, é importante compreender que a linguagem está sempre relacionada à sua exterioridade (as condições materiais de produção do discurso), ou seja, é analisada a relação entre o sujeito que fala e o contexto no qual esse dizer é produzido (Orlandi, 2013). Neste sentido, Pêcheux (2014) é taxativo ao argumentar que o sujeito não é autônomo (o sujeito psicológico coerente, centrado e racional é uma ilusão), mas sim ele é um efeito produzido pela interpelação ideológica ${ }^{1}$ - o sujeito é, portanto, efeito e não causa da linguagem.

Outro razão que levou à escolha desses textos-filmes foi suas altas bilheterias, ou seja, seu impacto como cultura de entretenimento de massas. Valente vendeu no Brasil quase três milhões de ingressos (Adoro Cinema, 2012; IMDB, 2016); Frozen pouco mais que quatro milhões de ingressos (Adoro Cinema, 2013; IMDB, 2016); e Malévola quase seis milhões de ingressos (Adoro Cinema, 2014; IMDB, 2016), números (e lucro) expressivo para exibições cinematográficas.

Ademais, de acordo com Bettelheim (2011), essas narrativas enraizadas nos contos de fadas influenciam fortemente o contexto infantil, visto que podem auxiliar a criança na constituição de sua identidade e comunicação. Nessa perspectiva, ao reconhecer o cinema como uma experiência cultural Giroux (2001) faz referência à importância da empresa Disney como produtora não somente de filmes, mas também de identidades contemporâneas.

Assim, buscou-se naqueles textos-filmes sentidos semelhantes nos discursos sobre as representações de gênero feminino ligadas à heteronormatividade, sendo destacadas as principais FD que expressam discursos (efeitos de sentidos) construídos nas narrativas, considerando a posição discursiva das personagens e outros argumentos relativos à cultura contemporânea que também se manifestam nessas produções (interdiscurso).

1 Pêcheux argumenta que não é o sujeito que é interpelado pela linguagem (compreendida como o sistema de regras simbólicas que organiza o dizer), pois isso suporia a anterioridade do sujeito diante da Ideologia - ilusão essa denominada de efeito Müchhausen), mas sim que a Ideologia preexiste e interpela o indivíduo em sujeito. 


\section{Resultados e Discussão}

Os resultados serão apresentados em duas seções. A primeira seção apresenta um resumo dos textos-filmes, destacando seus enredos e tramas principais. A segunda seção se debruça sobre as principais FD e objetos discursivos geradores de efeitos de sentidos naqueles textos-filme, sendo estas: FD 1) Feminilidade Hegemônica (que diz respeito ao modo pelo qual as princesas estão sendo representadas, considerando os padrões de feminilidade construídos historicamente); FD 2) Ato Heroico (que se refere ao ato heroico enquanto recente competência e domínio do gênero feminino); FD 3) Amor Romântico (que explora as possibilidades de o amor romântico assumir diferentes formas, não estando limitado ao ideal de completude entre masculino e feminino).

\section{Os textos-filmes}

Valente (2012) conta a história de Merida, uma princesa que quer viver sua vida livre dos ditames que sua condição de realeza exige. Ela é uma exímia arqueira, escaladora, e gosta de explorar lugares desconhecidos. Seu pai a vê como um reflexo de si mesmo e incentiva esses comportamentos da filha. Já sua mãe busca criá-la para ser a sucessora ao cargo de rainha e, para isso, enfatiza a etiqueta e os costumes relacionados ao esperado de uma princesa (modo de ser vestir, se comportar em público, atividades relacionadas à cozinha, costura e a importância do casamento). No entanto, as preferências de Merida são outras e é a partir disso que se inicia a relação conflituosa dela com a mãe, enredo principal do filme (Adoro Cinema, 2012).

Frozen (2013) tem como protagonistas as princesas-irmãs Elsa e Anna, que eram bem próximas durante a infância; no entanto, após um acidente envolvendo os poderes especiais de manipular gelo de Elsa fez com que seus pais as mantivessem afastadas. Após a morte dos pais em um naufrágio as duas cresceram isoladas no castelo, até o dia em que Elsa deveria assumir o trono daquele reino. No dia da coroação ela perde o controle e congela todo o reino, fazendo com que todos descobrissem seu segredo. Elsa foge com o intuito de se isolar e Anna inicia uma jornada em busca da irmã. $\mathrm{O}$ filme se desenvolve em torno dessa busca e tentativa de (re) construção da relação entre as duas irmãs (Adoro Cinema, 2013).

Malévola (2014) éo re-contodo clássicoA BelaAdormecidaa partir da perspectiva da suposta vilã. A protagonista é a própria Malévola e o filme traz sua história desde a infância até a idade adulta. Cresceu como rainha em um pacífico reino de criaturas mágicas que no decorrer da narrativa entra em conflito com o reino dos humanos. Determinada a se vingar após uma traição do rei dos humanos, Malévola amaldiçoa

2 Valente (2012) é a primeira produção da Pixar em parceria com a Disney a ter como protagonista uma personagem mulher. O filme também seria o primeiro do estúdio a contar com uma mulher na direção, mas após dezoito meses no cargo ela foi substituída por um homem. 
Aurora, filha recém-nascida de seu rival. Durante o conto, Malévola cria uma relação de afeto com Aurora e seu objetivo passa a ser tentar quebrar essa maldição (Adoro Cinema, 2014).

\section{Da superfície linguística aos objetos discursivos: as Formações Discursivas}

Os textos-filmes foram assistidos várias vezes em sua versão dublada e as cenas/ momentos considerados significativos foram anotados, visto que são direcionados (porém, não restritos) para o público infantil. Assim, ao longo das reproduções, segundo recomenda Banks (2009), as cenas que problematizavam o objeto desta pesquisa foram anotadas no formato de fichas (anotação do tempo, anotação e descrição da cena e das falas) que, ao final, foram compiladas num diário de campo.

\section{FD 1: Feminilidade Hegemônica}

Dentre as temáticas frequentemente abordadas pelos contos de fadas (clássicos ou contemporâneos), evidencia-se uma constante preocupação com o modo pelo qual as princesas são representadas. Logo, nos textos-filmes há discursos que tangenciam os padrões de feminilidade constituídos historicamente. De acordo com Wolf (1992), em relação ao conceito de feminilidade, incluindo àqueles representados nos contos de fadas, observa-se uma perpetuação de características como docilidade, submissão, compaixão e, principalmente, a constante vontade de atingir um ideal de beleza. Dessa forma, as princesas (que fazem parte do imaginário de uma sociedade) representam uma forma estereotipada do que é ser mulher.

Em uma das primeiras cenas do filme Valente, o pai (Fergus) de Merida a presenteia com um arco eflecha e prontamentea mãe se posiciona contrariamente: "Um arco Fergus? Ela é uma dama" (02'15") 3. Ao usar a palavra dama como justificativa para a censura do presente, automaticamente geram-se efeitos de sentido que delimitam o lugar que Merida deve ocupar em decorrência de seu gênero. Caso outras palavras (por exemplo, criança) ou frases (por exemplo, ela pode se machucar) fossem proferidas pela mãe elas gerariam sentidos diferentes que não necessariamente perpassariam o fato de Merida ser uma personagem que deveria se enquadrar nos padrões de gênero feminino.

De acordo com Orlandi (2013) e Pêcheux (1997) esse movimento discursivo exemplifica e denuncia tanto o efeito metafórico do discurso (todo sentido é constituído em relação a outro sentido, ou seja, por paráfrase em relação ao

3 Preferimos para melhor orientar o leitor destacar entre parênteses os minutos e segundos nos quais as superfícies linguísticas (os excertos de fala dos textos-filme) foram retiradas. Esse procedimento pode auxiliar (na análise do discurso) na compreensão do contexto específico da produção dos discursos. 
interdiscurso ou memória discursiva) como visa anular o Esquecimento Número 2: supomos (pensamos) que o que dizemos só pode ser dito com aquelas exatas palavras e não outras, ou seja, há uma ilusão de domínio da fala e do discurso por parte do sujeito produtor e uma ilusão de transparência entre o pensamento (consciente) e o dizer. É importante destacar que após a configuração dos corpora (delimitação das superfícies linguísticas) este é o segundo passo metodológico (transformação da superfície linguística em objeto discursivo) da AD.

Nesse recorte, o termo dama atrelado à construção social que perpassa o gênero feminino denuncia processos sociais de regulação e controle de feminilidade atrelados à FD e à Formação Ideológica, sendo este último atingido pelo Esquecimento Número 1. No decorrer das cenas, observam-se diferentes colocações de Elinor (mãe) que buscam representar o gênero feminino de maneira ideal. Isso é exemplificado nas seguintes superfícies linguísticas: "Uma princesa deve mostrar conhecimento sobre o seu reino, ela não faz desenhos. Uma princesa não ri assim” (o6’16”); “Não enche muito a boca. Deve cedo levantar. Deve ter compaixão. Ser paciente, cautelosa, asseada. E acima de tudo uma princesa busca a perfeição" (o7'13”). É interessante observar como a sucessão dos adjetivos (cautelosa; paciente; asseada) circunscrevem um lugar marcadamente feminino, cuja figura da princesa congregaria qualidades idealizadas que a cultura dominante atribui como significativos para a feminilidade.

Em termos metodológicos, o passo seguinte ao estabelecimento do objeto discurso é incidir a análise sobre o processo discursivo (Pêcheux, 1997), ou seja, tentar compreender aspectos da zona de funcionamento do Esquecimento Número 1. Este esquecimento segundo Pechêux (1997) e Orlandi (2013) está relacionado ao esquecimento ideológico e inconsciente que reproduz em nossos discursos o modo pelo qual somos afetados pela Ideologia, ou seja, nosso desconhecimento acerca das condições (materiais) de produção dos discursos. No recorte "uma princesa nem deve possuir armas, na minha opinião" (o6'16”) (Elinor) pressupõem-se que a escolha da expressão "na minha opinião" carrega a ilusão de que a personagem é a origem absoluta desse dizer, quando na realidade tal dito está ligado aos sentidos e ideologias pré-existentes na sociedade (interdiscurso), entendendo Ideologia como um processo que legitima conjunto de sentidos (de uma classe social) que prescreve condutas e pensamentos a todos os membros de uma sociedade (Chauí, 2012; Pêcheux, 2014).

Outro aspecto que exemplifica os lugares que são diferentemente ocupados pelo masculino e feminino pode ser visualizado quando Merida se manifesta a respeito de seus três irmãos:

Eles podem fazer qualquer coisa e eu nunca posso fazer nada. $\mathrm{Eu}$ sou uma princesa. Eu sou o exemplo. Tenho deveres, responsabilidades, expectativas. Minha vida inteira foi planejada me preparando para o dia em que me tornarei, bom... minha mãe. Ela manda em cada dia da minha vida (Valente, 2012, 05'21") 
A partir dessa superfície linguística observa-se como o interdiscurso está presente no discurso da personagem. $\mathrm{O}$ interdiscurso pode ser entendido como tudo aquilo que já foi dito e foi esquecido, além de outros sentidos que competem pela legitimidade do dizer que, conjuntamente, determinam o dizer (Orlandi, 2013). Para Pêcheux (1997), os discursos (portanto, o campo do interdiscurso) são afetados pelos efeitos de dominância, isto é: dado a isomorfia dos sentidos dos discursos estabelecida pelo efeito metafórico os sentidos que se sobrepõem aos demais o fazem por causa de relações de poder de uma sociedade. Em outras palavras, a relevância de um sentido sobre outros se dá pela força do convencimento (que por vezes se estabelece por meio da força real).

Nesse sentido, é o interdiscurso que justifica/explica o sentido de que o masculino não deve responder aos deveres e responsabilidades próprios ao feminino. Ao dizer que eles (masculino) podem fazer qualquer coisa e ela (feminino) não pode fazer nada são estabelecidas posições assimétricas entre os gêneros. Segundo Petry \& Meyer (2011), essas concepções generificadas (engendered), culturalmente legitimadas e naturalizadas pela Ideologia, pautam o sistema heteronormativo. Ou seja, normas regulatórias reiteradas assumem o caráter (e o efeito) de normalidade, servindo de munição a um processo que visa disciplinar formas típicas de masculinidades e feminilidades, bem como munir um processo ideológico que supõem os homens superiores às mulheres.

Situações semelhantes são encontradas em Frozen (2013). Quando na cena da festa de coroação da Rainha Elsa, dois convidados estão conversando e o primeiro diz: "Meus olhos cansados mal podem esperar para ver a rainha e a princesa, aposto que são adoráveis" (12'40"), logo em seguida o segundo responde: "Aposto que são muito lindas" (12'42"). Os termos adoráveis e lindas além de afirmarem que a feminilidade é baseada majoritariamente na aparência física ao serem proferidos por personagens do gênero masculino (em conjunto com a expressão "meus olhos cansados") produzem efeitos de sentido que remetem à importância do ideal de beleza feminina como forma de satisfazer o masculino.

Isso gera efeitos que atestam que as imagens dominantes das princesas nos textos-filmes são construídas pelo e para o olhar masculino. Caso algum dos convidados tivesse falado, por exemplo, "aposto que são inteligentes" (produção do objeto discursivo via polissemia) isso produziria sentidos diferentes, com expectativas que não perpassariam os condicionantes de beleza que os ideias de feminilidade propõem - fato este que remete ao Esquecimento Número 2 citado anteriormente.

Em Malévola (2014) observam-se movimentos análogos aos discorridos como, por exemplo, na cena em que uma das fadas madrinhas está presenteando Aurora após seu nascimento. A partir da superfície linguística "Doce Aurora, eu te concedo o dom da beleza" (28'14"), pode-se considerar que ao relacionar a palavra dom - sendo seu significado mais usual e cristalizado atribuídoà dádiva, benefício, talento e dote natural (Ferreira, 2004) - com beleza, pressupõe-se que tal característica é de fundamental importância ao gênero feminino. Torna-se interessante ressaltar também a escolha da palavra doce para qualificar a personagem, sendo essa família parafrástica (doce; dom; 
beleza) relacionadas ao efeito metafórico do discurso (Pêcheux, 1997), numa maneira de reforçar as atribuições do gênero feminino de acordo com as expectativas sociais tradicionais.

Em contrapartida, algumas cenas dos filmes denunciam recusas por parte das protagonistas em assumirem plenamente as características atribuídas ao gênero feminino. Isso pode ser compreendido como um dos efeitos de dominância do interdiscurso (Pêcheux, 1997). Por exemplo, em Valente (2012), Merida se mostra claramente contra as imposições feitas pela mãe; ela diz: "Mas de vez em quando tem um dia onde [sic.] eu não preciso ser uma princesa. Nada de lições, nem expectativas. Um dia onde [sic.] qualquer coisa pode acontecer. Um dia em que posso mudar o meu destino" (o7'21"). Enquanto esse dizer é proferido a personagem caminha em direção ao estábulo e inicia uma jornada pela floresta junto ao seu cavalo, treinando suas habilidades com o arco e flecha e escalando montanhas. Ao evidenciar que existe um dia em que não precisa ser princesa e as cenas seguintes mostrarem atividades culturalmente associadas ao gênero masculino, evidencia-se o posicionamento de Merida frente aos ensinamentos de mãe que a princípio são significados como a forma única e correta de existência enquanto princesa. Quando enfatiza que ela pode mudar seu destino, observa-se a Ideologia operando (Pêcheux, 2014), visto que o destino pode ser entendido como maneira de perfomatizar sua identidade de gênero de forma restritiva segundo códigos de conduta e aparência em consonância com as normas de feminilidade.

Outro ponto importanteéa forma pela qual Merida se filia ao universo discursivo masculino. Para além de seus interesses por atividades socialmente consideradas desviantes do feminino a personagem possui cabelos ruivos (assim como seu pai e irmãos) diferentemente de sua mãe (cabelos castanhos). Essa característica física gera efeitos de sentidos que a aproxima do pai e a distancia da mãe - podendo ser parafraseados naquele contexto para masculino e feminino.

Em Frozen (2013), logo após os dois convidados do baile de coroação manifestarem suas expectativas quanto à rainha e a princesa (lindas e adoráveis) a cena seguinte apresenta Anna instantes antes de despertar, com os cabelos bagunçados, roncando e babando. Nesse momento, é importante o contraste entre as cenas (superfícies linguísticas), contrapondo as expectativas dos dois homens com o modo como a princesa se apresenta. Em outros momentos do filme a princesa Anna mostrase com características desviantes do esperado visto que apresenta comportamentos desastrados, quebrando partes da decoração do castelo onde vive, andando de forma desajeitada, entre outros.

O encontro entre o Príncipe Hans e a Princesa Anna se dá a partir de um acidente em que o príncipe a derruba dentro de um barco. As cenas subsequentes são uma série de movimentos desajeitados de ambos para retirá-la do barco e em seguida o príncipe se desculpa pelo acontecido. Anna responde dizendo: "Não, não, não. Tudo bem. Não sou esse tipo de princesa. Quer dizer... Se fosse com a minha irmã Elsa ela daria um chilique. Sabe como é. Mas para sua sorte sou só eu" (17’o4"). Ao dizer que "não é esse tipo de princesa" sem antes explicar a qual tipo de princesa está se 
referindo (implicitamente, a tradicional do cinema clássico de animações) denunciase a presença tanto do interdiscurso como do efeito de dominância dos discursos (Pêcheux, 1997) - no caso, do tradicionalismo de gênero que associa as figuras princesa e mulher. Para Orlandi (2013) a constatação do interdiscurso permite associar os dizeres das personagens à memória discursiva, revelando seus compromissos (e apagamentos) ideológicos. No entanto, ao Anna dizer que "sou só eu" percebe-se que a personagem se coloca em posição inferior ao se comparar com o tipo tradicional (portanto, o considerado normal) de princesa.

Nesse sentido, embora em certos momentos os textos-filmes apontarem para a recusa dos sentidos cristalizados e heteronormativos referente ao gênero feminino, percebe-se, pelas filiações de sentidos construídos em outros dizeres, marcas ideológicas e de relações de poder que constituem e são constituintes dos sujeitos a despeito de suas vontades e escolhas.

\section{FD 2: Ato Heroico}

Convém notar que nos textos-filmes oato de heroísmo éo que possibilita oenlace final das histórias, assim como nos contos de fada em geral. No entanto, em nenhuma deles esse ato é realizado por personagens do gênero masculino. Em comparação aos contos de fadas clássicos, pode-se supor que esse inovador posicionamento das produções da Disney sugere um questionamento de paradigmas, visto que nos filmes mais antigos (clássicos) o ato de heroísmo estava restrito ao beijo de amor verdadeiro proporcionado pelo príncipe.

O fato destes textos-filmes atribuírem a uma personagem feminina o ato heróico propicia questionamentos a respeito da comum associação entre herói e masculino, pois de acordo com Cassal (2001) o herói é uma construção cultural associada ao mundo masculino. Por exemplo, em Frozen (2013), após ser atingida acidentalmente pelos poderes de congelamento da irmã Elsa, Anna só pode ser salva por um ato de amor verdadeiro. Pelo fato de Anna ter se relacionado com o Príncipe Hans no início da narrativa tudo leva a crer que seria ele quem a salvaria. No entanto Hans afirma que não a beijará para desfazer o feitiço, pois seu objetivo era roubar o trono, revelandose o vilão da história. Em seguida, somos levados a supor que o próximo na lista de possíveis salvadores seria Kristoff, personagem que a princesa conheceu durante sua trajetória em busca da irmã. Nos momentos finais da narrativa Anna precisa escolher entre beijar Kriskoff para se salvar ou se sacrificar para salvar a irmã que está lutando com o Príncipe Hans. Ao perceber que Elsa está prestes a ser assassinada, Anna corre em sua direção e se posiciona entre os dois, salvando a irmã, sendo este o ato de amor verdadeiro.

Outro exemplo consta em Malévola (2014), visto que é a própria Malévola que ao beijar Aurora na testa quebra a maldição que ela mesma lançou no passado e isso só foi possível diante da relação de afeto que as duas criaram durante a narrativa. Em 
um primeiro momento, as personagens consideram que seria o Príncipe Philip que salvaria Aurora, no entanto no desenrolar da história essa alternativa é vista como absurda, afinal os dois se encontraram apenas uma vez e trocaram poucas palavras. A fala final do filme explicita a atribuição à mulher o que era destinado ao universo masculino: "No fim, meu reino foi unido não por um herói, ou um vilão, como a lenda dizia. Mas por alguém que foi heroína e vilã. E seu nome era Malévola” (87’11").

Nesse recorte, a substituição dos artigos definidos (designativos dos gêneros) herói/heroína para vilão/vilã produz efeitos de sentidos que possibilitam ao gênero feminino ocupar lugares antes vetados. Ademais o mesmo movimento analítico visando anular o Esquecimento Número 2 por meio da paráfrase (herói/heroína; vilão/ vilã) pode ser obtido pela produção de polissemias (de "um herói, ou um vilão" para "heroína $e$ vilã") (Pêcheux, 2006). Nos textos-filmes ao possibilitar que o ato heróico seja realizado por uma personagem do sexo feminino alguns elementos simbólicos referentes à dominação masculina são postos em questionamento (ou em outras palavras, em disputa em outros efeitos de dominância), visto que esse ato destinavase exclusivamente ao masculino e os textos-filmes utilizados trazem isso como forma primeira de significação.

Em Valente, diferentemente de Frozen e Malévola (devido ao relacionamento entre mãe e filha ser o foco do enredo) em nenhum momento é possível ou suposto que o ato heroico possa ser realizado por personagens do gênero masculino. Ao final da história é a aproximação entre as protagonistas que quebra a maldição que fez com que Elinor (a mãe) se transformasse em urso.

Retomando ao contexto dos contos de fada tradicionais e enraizados no imaginário, a não realização dessa possibilidade gera sentidos significativos em relação à dominação masculina. Reiterando, de acordo com Orlandi (2013) e Pêcheux (2006; 2014), ao longo dos dizeres existe toda uma margem (franjas) de não-ditos (e de esquecimentos) que também significam e constituem os discursos. Portanto, ao representar (dizer) o ato heroico como pertencente ao universo feminino é possível perfilhar um possível empoderamentodo feminino. Isso permitenestas materializações discursivas (textos-filmes) problematizar os efeitos da heteronormatividade (isto é, representações e práticas que organizam a sociedade pela naturalização da heterossexualidade das relações de gênero), questionando a complementaridade (e mais precisamente a submissão) entre os gêneros.

De acordo com a AD essas tensões nos textos-filmes podem ser compreendidas como a tensão entre os processos de paráfrases (retorno aos mesmos espaços de dizer por meio do interdiscurso ou da memória discursiva) e de polissemias (ruptura com os processos de significação, ou ruptura com a família parafrástica) (Orlandi, 2013). Portanto, ao mesmo tempo em que essas produções cinematográficas retornam dizeres que enfatizam o ato heroico como decisivo à conclusão da trama (paráfrase), elas geram diferentes sentidos ao possibilitar que este ato seja realizado por sujeitos não masculinos (polissemia). Nesse sentido, é neste embate entre paráfrase e polissemia que os sujeitos e os sentidos se articulam e significam no contexto sócio histórico em que são construídos. 


\section{FD 3: Amor Romântico}

Um dos pontos frequentemente enfatizados pelas animações da Disney é a ideação do amor romântico. De acordo com Neves (2007) as concepções sobre o amor são importantes para a organização cultural e social, pois definem (de forma não diretiva e por meio dos papeis de gênero protagonizados em torno do romanticismo) o que é apropriado e desejável para e entre os indivíduos, bem como sugerem atitudes definidas para cada um dos sexos.

É possível observar em alguns momentos dos textos-filmes situações que problematizam o ideal de amor romântico. Em Frozen (2013) durante a festa de coração de Elsa sua irmã Anna a surpreende pedindo que abençoe o casamento dela com o Príncipe Hans, o qual havia encontrado pela primeira vez naquele mesmo dia. Ao que Elsa responde: "Não pode se casar com quem acabou de conhecer" (26'25"), Anna rebate à sua afirmação dizendo: "Posso sim, se for amor verdadeiro" (26'27"). Nesse contexto, a legitimidade da escolha pelo casamento é atribuída ao amor verdadeiro, aludindo discursivamente ao amor romântico heteronormativo presente nas narrativas dos contos de fadas. No entanto, questiona-se a naturalização dessa condição sublime direcionada ao amor verdadeiro: no decorrer da história esse príncipe acaba por se tornar o vilão, fato que novamente coloca em questão a escolha de Anna de se casar com uma pessoa que não teve tempo de conhecer apropriadamente.

O amor romântico tem sido o principal foco de críticas para alguns segmentos dos movimentos feministas, sendo a sua ideologia apontada como responsável por conduzir as mulheres a acreditar que a felicidade depende da sua entrega total e incondicional aos parceiros masculinos - o que também origina violências e desigualdades (Neves, 2007).

Em Valente (2012), após Merida se revoltar após ser informada pela mãe que os clãs vizinhos participarão de uma competição cujo vencedor terá o direito de se casar com ela (Merida), sua mãe responde: "Francamente Merida, eu não sei por que você está agindo assim. Foi para isso que se preparou toda sua vida" (12'10"). Ao afirmar que "foi para isso que ela se preparou durante toda sua vida", cristalizam-se efeitos de sentidos e modos de relações sociais impregnados pela ideologia patriarcal e sexista (em outras palavras, heteronormativa) que significam a mulher como objeto destinado ao casamento, sendo este um mecanismo de manutenção de uma condição submissa feminina diante o masculino.

No entanto, Merida contraria esse posicionamento ao replicar: "Não! Foi para isso que você me preparou toda a minha vida. Eu não vou aceitar isso. Não pode me obrigar" (12'12"); ou: "Eu sou Merida, primogênita descendente do clã Dun Broch e pela minha própria mão eu vou lutar" (26'o2"). Há nisto tanto um evidente movimento de afastamento da personagem ao condicionante de mulher submissa e criada para o casamento como uma aproximação ao lugar de primeiro filho gerado pelos pais, ou seja, aquele que tem seu lugar de herança e poder de escolha por direito, lugar esse ocupado pelos descendentes (todavia, homens) dos outros clãs. Essa mudança de 
posicionamento de Merida é discursivamente exemplificada pela utilização da palavra primogênita e não da palavra princesa para se autorreferir.

Essa sucessão de superfícies linguísticas que ocasionam alterações dos sentidos são exemplos do funcionamento da ilusão referencial pertencente ao Esquecimento Número 2 segundo o qual se supõe uma relação direta entre o pensamento, o dizer e o mundo/realidade (Pêcheux, 2014). Ou seja, é suposto que o que dizemos só pode ser dito com determinadas palavras e não com outras. No entanto, mesmo alterando o substantivo (de princesa para primogênita) que estabelece outros sentidos, mantémse a ilusão da dominação da produção do discurso pelo sujeito.

Outro aspecto que pode ser entendido como efeito de sentido nessa transição de superfícies linguísticas é o fato de que ao se candidatar para lutar pela sua própria mão, ela (Merida) consequentemente luta pelo direito de não secasar, contrapondo-seà instituição do casamento comumente associada e veiculada pela heteronormatividade. Todavia, a ilusão da autodefinição é mantida, típico do funcionamento da Ideologia, na "medida em que ela se caracteriza por uma estrutura e um funcionamento que fazem dela uma realidade não histórica [...] no sentido em que esta estrutura e este funcionamento se apresentam na mesma forma imutável em toda história" (Pêcheux, 2014, p.151).

Com a vitória de Merida no torneio a cena seguinte resulta na ruptura entre mãe e filha, rompimento este representado por um corte em uma tapeçaria que retrata a família, dividindo a figura materna e filial. Com o desenrolar da história as duas personagens se aproximam apesar das diferenças apontadas e é por meio dessa aproximação que o amor verdadeiro do filme é simbolizado, pois o amor não necessariamente se restringe a completude entre masculino e feminino, podendo assumir diferentes formas.

Em uma das cenas finais do filme Merida se coloca diante do reino e proclama: "Eu decidi fazer o que é certo e quebrar a tradição. Minha mãe, a rainha, sente em seu coração que eu... nós estamos livres para escrever nossa própria história. Seguir nossos corações e encontrar o amor no tempo certo" (67'15”). Ao fazer isso Merida defende o direito de todos os herdeiros dos clãs (incluindo ela, incluindo as mulheres) se casarem com quem e quando quiserem, ou até mesmo não se casarem. Levando em conta o enredo do texto-filme e o constante posicionamento adverso de Merida frente aos ensinamentos da mãe, a expressão quebrar a tradição pode ser compreendida, por paráfrase, de diversas maneiras: quebra do lugar que necessariamente ocuparia enquanto princesa e as condições impostas a isso, questionamento dos ideais de beleza e condutas referentes ao feminino etc.

Em Malévola (2014) a temática do amor verdadeiro é tratada de forma diferente, uma vez que em diversos momentos do filme a protagonista afirma que ele não existe. Ao lançar a maldição em Aurora Malévola sentencia a princesa a um sono profundo até os seus dezesseis anos e do qual só acordará com o beijo de amor. Quando Aurora, já crescida, encontra o Príncipe Philip na floresta por acaso, o corvo que Malévola transforma em humano para que seja seu aliado cogita a hipótese de que o príncipe seria a solução para que a princesa se livrasse da maldição, Malévola declara: "Amor 
verdadeiro? Você não compreendeu ainda. Eu fiz isso porque não existe amor verdadeiro" (61'15”).

Essa crença de Malévola na não existência no amor verdadeiro apóiase na definição do mesmo enquanto exclusivo entre homem e mulher, ou seja, heteronormativo. Mas é preciso referir que ainda criança Malévola conhece um garoto chamado Stefan e os dois vivem um amor juvenil. Porém, na vida adulta o rapaz se distancia de Malévola motivado por sua ambição e busca por poder. Após uma batalha do rei contra os seres da floresta é determinado que quem matar Malévola terá o trono como recompensa. Stefan, decidido a se tornar rei, retorna à floresta e trai Malévola, cortando suas asas e tomando o reino dos humanos para si. Isso exemplifica a memória discursiva interdiscursiva que sustenta a produção dos sentidos (Orlandi, 2013; Pêcheux, 2006), tal como proferido por Malévola acerca da inexistência do amor verdadeiro.

A polissemia também pode ser evidenciada na cena em que Malévola tem as asas cortadas: para-além de uma simples conquista de um reino por um homem isso pode ser entendido como uma analogia à violência contra a mulher. No entanto, por ser um filme destinado ao público infantil esse sentido (violência) transcorre de maneira implícita.

É depois e diante desse fato que Malévola passa a acreditar que o amor verdadeiro não existe, visto que a pessoa que ela amava usou dessa posição para traí-la. Quando Malévola se aproxima de Aurora para se desculpar por ter lançado a maldição, mesmo Aurora estando em sono profundo, Malévola a beija sobre a testa e visivelmente se surpreende ao ver que este teria sido o beijo de amor. Nesse momento do texto-filme novamente questiona-se o ato de amor verdadeiro como sendo restrito entre o masculino e feminino, permitindo diferentes interpretações e formas de amor verdadeiro como, por exemplo, o entre mulheres.

Mesmo considerando a impossibilidade deacesso total às condições de produção das FD, das Formações Ideológicas e da própria Ideologia na produção dos discursos (representado pelo Esquecimento Número 1), tal acesso pode ser oportunizado pelo desvelamento de funcionamento do Esquecimento Número 2. Sumariamente, para que seja possível compreender as condições de produção dos discursos torna-se essencial atentar-se ao momento sócio histórico em que são produzidos (interdiscurso e condições materiais de produção) (Pêcheux, 2014).

Segundo Kellner (2001), filmes são indicadores sociais importantes de um período histórico uma vez que uma enorme quantidade de capital (humano, financeiro, simbólico, logístico etc.) é investida em pesquisar, desenvolver e comercializar as produções cinematográficas. Assim, essas variações e ou conflitos de representatividade em torno da imagem feminina veiculada pelos três textosfilmes não são uma invenção contemporânea unicamente originária do conglomerado Disney. 
Partindo do pressuposto de que não há discurso que não se relacione com outros (interdiscurso) sendo os efeitos de sentido resultantes desses embates (Orlandi, 2013), entende-se que os discursos presentes nesses textos-filmes apontam para outros que o sustentam e com os quais concorrentemente constroem sentidos. Neste corpora específico não se pode desconsiderar que os questionamentos dos padrões estéticos, culturais e comportamentais do universo feminino (por intermédio das personagens) em contraste com as representações hegemônicas do feminino respondem tanto aos movimentos feministas contemporâneos (que anseiam por novas representações, práticas e sentidos para as mulheres) como aos apelos do mercado de consumo (feminino e infantil), visto que são potenciais públicos consumidores em concorrência e coexistência com estratos populacionais tradicionais no que se refere às relações entre e intragêneros - elementos estes componentes do processo discursivo que os constituem (Pêcheux, 2014).

\section{Apontamentos Finais}

No esforço de compreender os discursos (e seus efeitos de sentido) ligados ao gênero feminino e à heteronormatividade presentes nos três textos-filmes é possível considerar que essas produções cinematográficas de animações estão dotadas de elementos semânticos e simbólicos que proporcionam discussões sobre o modo como o gênero feminino está sendo representado.

Ao considerar que essas produções partem de uma corporação (empresa cinematográfica) que se situa em um lugar (de dizer) de destaque no processo de mercantilização da cultura, entende-se que a extensão do seu poder institucional e ideológico atinge consideráveis contingentes populacionais. Diante disso, compreende-se que ao problematizar questões e sentidos referentes às representações da feminilidade, do ato heroico e da busca pelo ideal de amor romântico, essas produções atuam de forma a familiarizar o público (dentre eles o infantil) com determinados tipos de identificações que em alguns momentos (implicitamente) questionam à lógica heteronormativa que visa regular e normatizar instituições e subjetividades generificadas.

De modo geral, esses textos-filmes da Disney não se constituem por meio de uma narrativa de romance invariavelmente heterossexual, visto que não há o reforço deste romance no enlace final legitimado pelo casamento e a comum associação do mesmo ao destino imutável do viveram felizes para sempre. Observa-se também que ao possibilitar o questionamento sobre a constituição da feminilidade, certas imagens/ sentidos cedem espaços a outras, corroborando com a possível representação de uma nova mulher que, relativamente, se afasta das definições convencionais de feminilidade hegemônica rigidamente circunscrita a casa, à família (nuclear burguesa) e à busca de completude através do amor romântico propiciadas pelo homem. A despeito disso, é interessante também considerar essas produções em consonância com as 
demandas contemporâneas dos movimentos feministas e do mercado de consumo que reivindicam inovadores padrões estéticos, culturais e atitudinais para as mulheres.

Considerando o momento histórico em que estão sendo produzidos, esses filmes tecem discursos (e sentidos) que sugerem fissuras nas matrizes hegemônicas referentes e delimitadoras do feminino, possibilitando questionamentos acerca da naturalização da heteronormatividade enquanto forma prioritária de configuração das relações entre e intragêneros. Todavia, ainda é evidente nestas produções a presença ambivalente de efeitos de sentidos e instituições tradicionais de gênero, como o casamento, a maternidade, o sexismo e o modelo de família patriarcal e/ou nuclear burguês. Pode-se, em suma, considerar essas produções cinematográficas como espaços (discursivos) de tensão e contradição entre aspectos tradicionais e inovadores do gênero e da feminilidade na contemporaneidade.

Não se pode também desconsiderar que esta pesquisa é um recorte, portanto, parcial, da realidade e das produções deapenas uma empresa cinematográfica (Disney), sendo necessário que outras investigações ampliem (em número e em tipologia) as produções a serem analisadas. Ademais, entende-se que abordar outros produtos culturais (provenientes de outras mídias) que também interpelam os indivíduos em sujeitos (no caso, sujeitos femininos) seria de grande importância para a compreensão do modus operandi das tecnologias de gênero enquanto dispositivos produtores e legitimadores de subjetividades.

Diante do exposto, considera-se que essa pesquisa, que pretendeu compreender os discursos (e seus efeitos de sentido) ligados ao gênero feminino e à heteronormatividade concernentes à filmografia contemporânea da Disney, cumpriu com seus objetivos.

\section{Referências}

ADORO CINEMA (2012). Valente: Sinopses e Detalhes. Disponível em: http://www. adorocinema.com/filmes/filme-135528/. Acesso em: o8 jun 2016

ADORO CINEMA (2013). Frozen: Sinopses e Detalhes. Disponível em: http://www. adorocinema.com/filmes/filme-203691/. Acesso em: o8 jun 2016

ADORO CINEMA (2014). Malévola: Sinopses e Detalhes. Disponível em: http://www. adorocinema.com/filmes/filme-201429/. Acesso em: o8 jun 2016

ALTHUSSER, Louis (2010). "Ideologia e aparelhos ideológicos do Estado (notas para uma investigação)”. In: ZIZEK, Slavoj. (org.). Um mapa da ideologia. Rio de Janeiro: Contraponto. p.105-142

ARAÚJO, Maria de Fátima (2005). "Diferença e igualdade nas relações de gênero: revisitando o debate”. Psicologia Clínica, 17, 2: p.41-52 
BANKS, Marcus. (2009). Dados visuais para pesquisa qualitativa. Porto Alegre: Artmed BETTELHEIM, Bruno. (2011). A Psicanálise dos Contos de Fada. São Paulo: Editora Paz e Terra

BOURDIEU, Pierre (2007). A dominação masculina. Rio de Janeiro: Editora Bertrand Brasil

BUTLER, Judith (2015). Problemas de gênero: feminismo e subversão da identidade. Rio de Janeiro: Civilização Brasileira

CAREGNATO, Rita Catalina Aquino \& MUTT, Regina (2006). "Pesquisa qualitativa: análise de discurso versus análise de conteúdo". Texto Contexto Enfermagem, 15, 4: p.679-684

CASSAL, Alex Barros (2001). A solidão do herói: prisão, clandestinidade, exílio e outros isolamentos no cinema brasileiro. Monografia Graduação em História. Universidade Estadual do Rio de Janeiro. Rio de Janeiro, RJ

CHAMBERS, Samuel (2003). "Telepistemology of the Closet; Or, the Queer Politics of Six Feet Under”. Journal of American Culture, 26, 1: p.24-41

CHAUÍ, Marilena (2012). O que é Ideologia? São Paulo: Brasiliense

DE LAURETIS, Teresa (1994). “A tecnologia de gênero". In: HOLANDA, Heloísa Buarque de (Org.). Tendências e impasses: o feminismo como crítica cultural. Rio de Janeiro: Rocco. p.206-242

FERNANDES, Wânia Ribeiro \& SIQUEIRA, Vera Helena Ferraz de (2010). “O cinema como pedagogia cultural: significações por mulheres idosas”. Estudos Feministas, 18, 1: p.101-119

FERREIRA, Aurélio Buarque de Holanda (2004). Novo Dicionário Aurélio da Língua Portuguesa. Curitiba: Positivo

FREIRE, João Freire (2005). "Força de expressão: construção, consumo e contestação das representações midiáticas das minorias”. FAMECOS, 1, 28: p.18-28

GIROUX, Henry (2001). “Os filmes da Disney são bons para seus filhos?" In: STEINBERG, Shirley \& KINCHELOE, Joe (Orgs). A construção corporativa da infância. Rio de Janeiro: Civilização Brasileira. p.87-108 
IMDB - Internet Movie Database (2016). Box Office. Disponível em: http://www.imdb. com/chart/boxoffice?ref_=nv_ch_cht_1. Acesso em: o8 jun 2016

JAGOSE, Annamarie (1996). Queer Theory: An Introduction. New York: New York University Press

KELLNER, Douglas (2001). A cultura da mídia - estudos culturais: identidade e política entre o moderno e o pós-moderno. São Paulo: EDUSC

MISKOLCI, Richard (2009). "A teoria queer e a sociologia: o desafio de uma analítica da normalização”. Sociologias, 21: p.150-182

NEVES, Ana Sofia Antunes das (2007). "As mulheres e os discursos genderizados sobre o amor: a caminho do "amor confluente" ou o retorno ao mito do "amor romântico?". Revista Estudos Feministas, 15, 3: p.609-627

ORLANDI, Eni Puccinelli (2013). Análise do Discurso: Princípios e Procedimentos. Campinas: Pontes

PÊCHEUX, Michel \& FUCHS, Catherine (1997). "A propósito da Análise Automática do Discurso: atualização e perspectivas”. In: GADET, F. \& HAK, T. (Org). Por uma análise automática do discurso: uma introdução à obra de Michel Pêcheux. Campinas: UNICAMP. p.163- 251.

PÊCHEUX, Michel (1997). “Análise Automática do Discurso (AAD-69)”. In: GADET, F. \& HAK, T. (Org). Por uma análise automática do discurso: uma introdução à obra de Michel Pêcheux. Campinas: UNICAMP. p.61- 161.

PÊCHEUX, Michel (2006). O Discurso: estrutura ou acontecimento. Campinas: Pontes PÊCHEUX, Michel (2014). Semântica e Discurso: uma crítica à afirmação do óbvio. Campinas: Unicamp

PETRY, Analídia Rodolpho \& MEYER, Dagmar Elisabeth Estermann (2011). "Transexualidade e heteronormatividade: algumas questões para a pesquisa". Textos $\mathcal{E}$ Contextos (Porto Alegre), 10, 1: p.193-198

PIRES, Suyan Maria Ferreira (2009). "Amor romântico na literatura infantil: uma questão de gênero”. Educar em Revista. 35: p.81-94

SABAT, Ruth Ramos (2001). "Infância e gênero: o que se aprende nos filmes infantil". Revista da Reunião Anual da Associação Nacional de Pós-Graduação e Pesquisa em Educação (ANPED). 24: p.1-15 
SCOTT, Joan (1995). “Gênero: uma categoria útil de análise histórica”. Educação e Realidade, 20, 2: p.71-99

SEIDMAN, Steven (1996). Queer Theory Sociology. Oxford: Blackwell

WARNER, Michael (1993). Fear of a Queer Planet: queer politics and social theory. Minneapolis/London: University of Minnesota Press

WOLF, Naomi (1992). O mito da beleza: Como as imagens de beleza são usadas contra as mulheres. Rio de Janeiro: Rocco

\section{Filmografia Utilizada:}

FROZEN: Uma aventura congelante. Direção: Chris Buck e Jennifer Lee. Produção: Walt Disney Pictures. (2013). 108 min. cor.

MALÉVOLA. Direção: Robert Stromberg. Produção: Walt Disney Pictures. (2014). 97min. cor.

VALENTE. Direção: Mark Andrews e Brenda Chapman. Produção Pixar Animation Studios/Walt Disney Pictures. (2012). 93 min. cor.

Recebido: 13.09.2017

Aceito: 30.05 .2018 